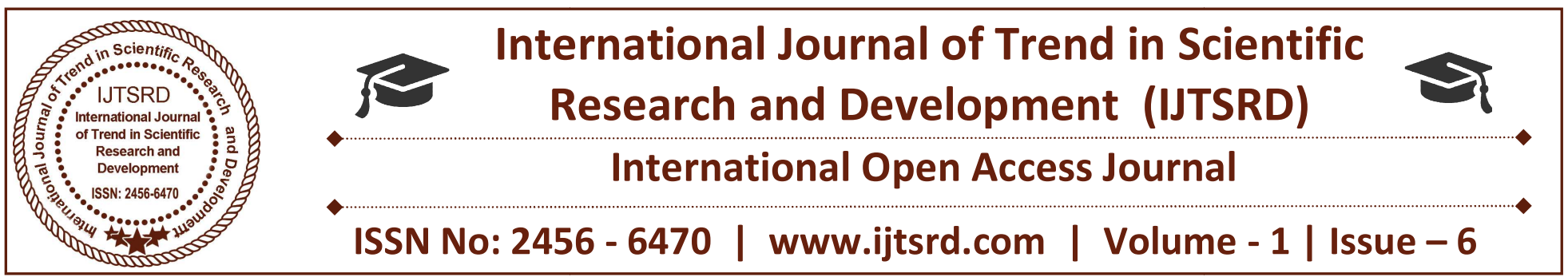

\title{
A Review on Economical and Technical Analysis for Modelling of Hybrid Energy System
}

\author{
P. Mahesh \\ Department of Electrical and \\ Electronics Engineering, GMR \\ Institute of Technology, AP, India
}

\author{
D. Srikanth \\ Department of Electrical and \\ Electronics Engineering, GMR \\ Institute of Technology, AP, India
}

\author{
K. Srinu \\ Department of Electrical and \\ Electronics Engineering, GMR \\ Institute of Technology, AP, India
}

\begin{abstract}
Energy demand is increasing day by day due to globalization and population. So that by using nonrenewable sources we cannot reach this energy demand because of increased cost per generation. And also from these sources pollution occurs is also more. So that if we use renewable sources, we can meet this energy demand. This paper gives review on different optimization methods of HES such as by using Artificial intelligence methods, by using software tools, by ensuring maximum energy production from low cost energy sources, by using DSM strategy and by using hybrid models. Finally, comparison and results are discussed.
\end{abstract}

Keywords: Software tools, HOMER, Genetic Algorithm, low cost energy source, DSM strategy, optimization

\section{INTRODUCTION}

Day by day energy consumption has increased due to globalization. In past, several years we had main sources for generating electricity are fossil fuel and nuclear energy sources. Which causes environmental pollution and green-house emissions. And also from these sources we can't give power supply to the rural areas because these sources are connected to normal grid. In this normal grid, some drawbacks are there such as increase in cost per unit generation, poor voltage regulation due to increased distance between grid to consumer load, low load factor, high cost as well as more time taken to erect the long transmission lines. So that if we use hybrid energy system by locally available sources, we can get low cost per unit generation. Therefore, technical and economical analyses of a hybrid energy system are essential for the efficient utilization of renewable energy resources [13].

This paper is organized as follows: section 2 provides different optimization methods. Section 3 provides results and discussions. Finally, conclusion is given in section 4.

\section{DIFFERENT TECHNIQUES}

OPTIMIZATION

\section{A) By using Artificial Intelligence Methods}

a) Genetic Algorithm approach:

One of the optimization methods operates in terms of the genetic process for biological mechanisms called Genetic Algorithm [13].

The given fig: 1 gives the idea about working of this GA. In this first it chooses the initial population called collection of individuals and then it selects the more fitted individual among all the individuals. After that it applies some changes through crossover and mutation process. Here crossover process means, combine two are more selected individuals to form new individual and mutation process means, apply random changes to selected individuals to form new individual. Finally, it evaluates the individual fitness of new individual and replaces the least fitness with the new population [8]. 


\section{b) Particle Swarm Optimization (PSO):}

Particle swarm optimization (PSO) is a population based stochastic optimization technique developed by Dr. Eberhart and Dr. Kennedy in 1995, inspired by social behavior of bird flocking or fish schooling.

Initially a random population is generated and fitness value is calculated. By taking the best fitness value into consideration the best population is selected and by updating process is done to it and new generation is created and then checks for the new optimal solution. The process continues until the optimal solution is obtained.

The population with high fitness function in each generation is taken as the local best solution and the population with high fitness value among all iterations is taken as the global best solution. The global best solution is taken as the optimal solution [8].

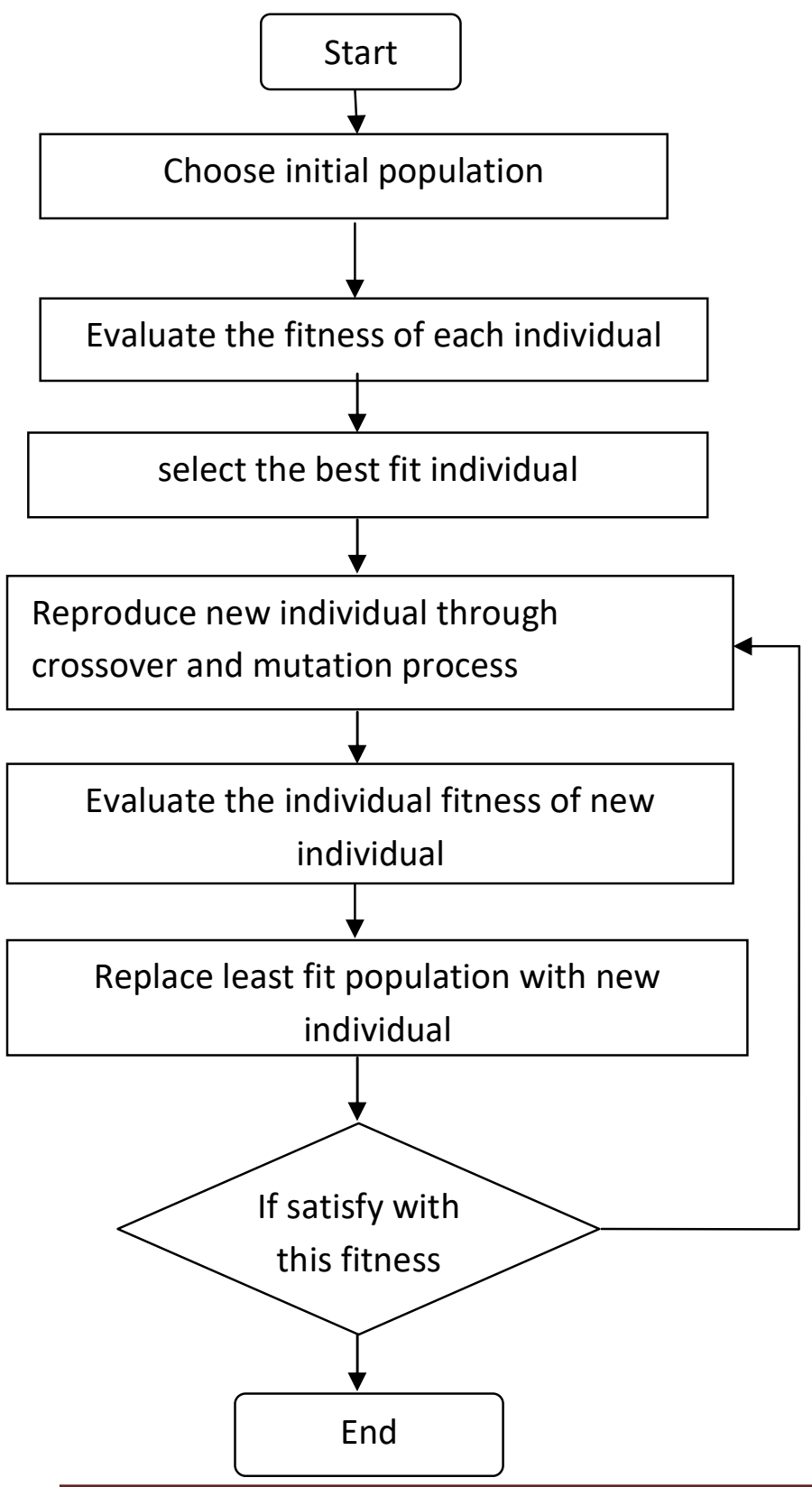

Fig 1: Flow chart for understanding Genetic Algorithm

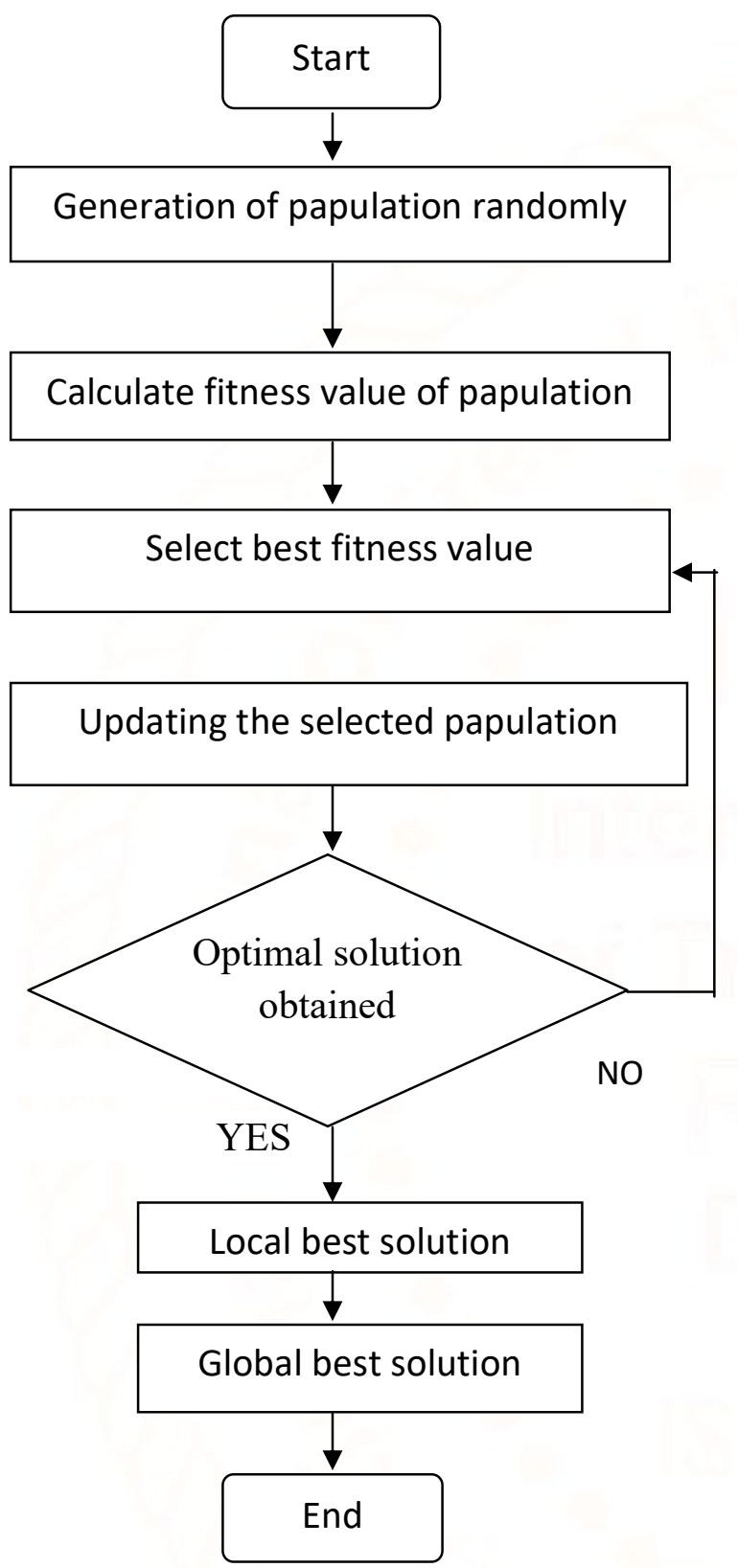

Fig 2: Flow chart for understanding PSO technique

B) By using software tools:

The technical and economical analyses of a hybrid system are essential for the efficient utilization of renewable energy resources. In this paper 19 software tools are reviewed namely HOMER, Hybrid2, RETScreen, iHOGA, INSEL, TRNSYS, iGRGYSO, HYBRIDS, RAPSIM, SOMES, SOLSTOR, HySim, HybSim, IPSYS HySys, Dymola/Modelica, ARES, SOLSIM and Hybrid- Designer.

It is observed that among all the tools HOMER is found to be widely sued tool in the research studies 
followed by RETScreen, HOGA, HYBRID2, TRNSYS and ARES [10].

Working of HOMER software tool is as follows,

INPUT

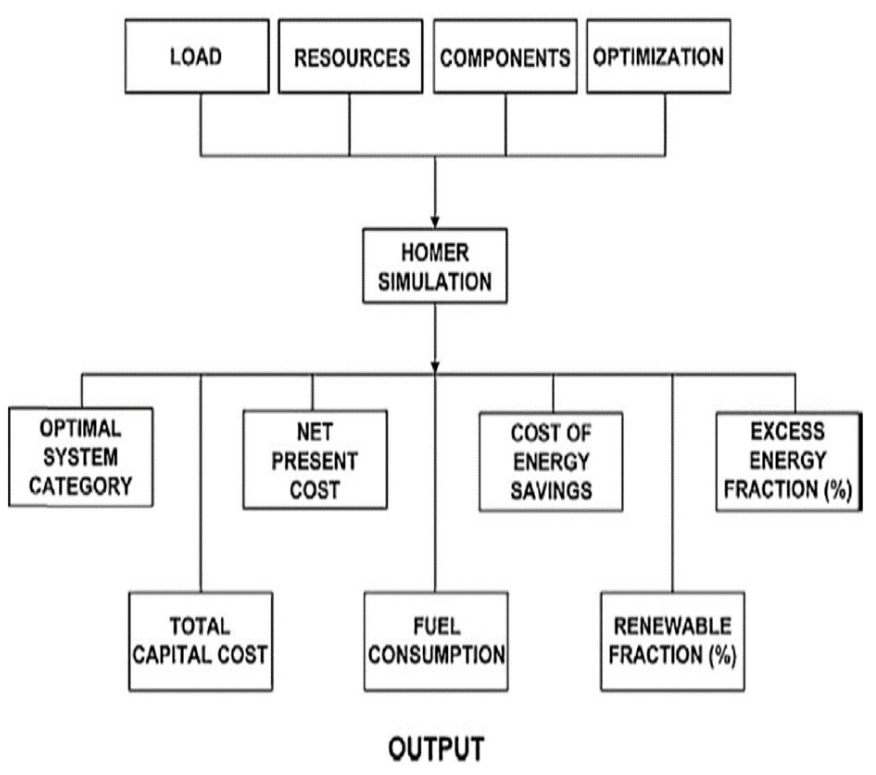

Fig 3: Architecture of HOMER software

The Hybrid Optimization Model for Electric Renewables (HOMER), is most widely used, freely available and user-friendly software. The National Renewable Energy Laboratory (NREL) USA has developed HOMER for both on-grid and off-grid systems in 1993 and from the Date of release, HOMER has been downloaded by over 80,000 people in 193 countries [10]. It takes the inputs as required load, no of resources (both renewable and nonrenewable sources for ensuring continuous and reliability of supply), cost of each components. Finally, if performs simulations and gives results in the form of optimal system category, total capital cost, net present cost, fuel consumption, cost of energy savings, renewable energy fraction (\%) and excess energy fraction (\%).

\section{C) By ensuring maximum energy production from low cost energy source:}

In this the total load is divided into two ways one is base load and other one is peak load. In this microhydro, solar, wind, biogas, Diesel generator and battery are the considered sources of HES system for understanding this method. In this our main aim is to reduce the cost per unit generation. In this we are taken non-renewable energy source for ensuring reliability of supply. In this HES system base load occurs continuously but peak load is not like that. so that base load is supplied by micro grid. This is because the power generated from this micro grid gives low cost per unit generation. if we use Diesel generator as a source in HES system for supplying base load, the cost of fuel required is very high and therefore the cost of unit generation is also more. Therefore, the sequence of power taken from these sources are as follows.

$$
\begin{aligned}
& \mathrm{Pd}=\text { power delivered by Diesel engine } \\
& \mathrm{Pbg}=\text { power delivered by biogas } \\
& \mathrm{Pw}=\text { power delivered by wind } \\
& \mathrm{Ps}=\text { power delivered by solar } \\
& \mathrm{Pb}=\text { power delivered by battery } \\
& \mathrm{Ppld}=\text { peak load power }
\end{aligned}
$$

When coming to peak load, this can be done by solar and wind sources when

$\mathrm{Pw}+\mathrm{Ps}>$ or $=$ Ppld. In this the extra power is stored in the battery. when the peak load is high i.e. $\mathrm{Pw}+\mathrm{Ps}<$ Ppld, then the power from the battery is connected to the hybrid grid i.e. $\mathrm{Pb}+\mathrm{Pw}+\mathrm{Ps}=\mathrm{Ppld}$. If $\mathrm{Pb}+\mathrm{Pw}+\mathrm{Ps}$ $<$ Ppld, then the biogas plant delivers power to the grid (i.e. $\mathrm{Pbg}+\mathrm{Pb}+\mathrm{Pw}+\mathrm{Ps}=\mathrm{Ppld}$ ). If this Ppld is greater, then the additional power is given by Diesel engine (i.e. $\mathrm{Pd}+\mathrm{Pbg}+\mathrm{Pb}+\mathrm{Pw}+\mathrm{Ps}=\mathrm{Ppld}$ ). In this way, we can reduce the dependency on fossil fuel sources and cost of unit generation.

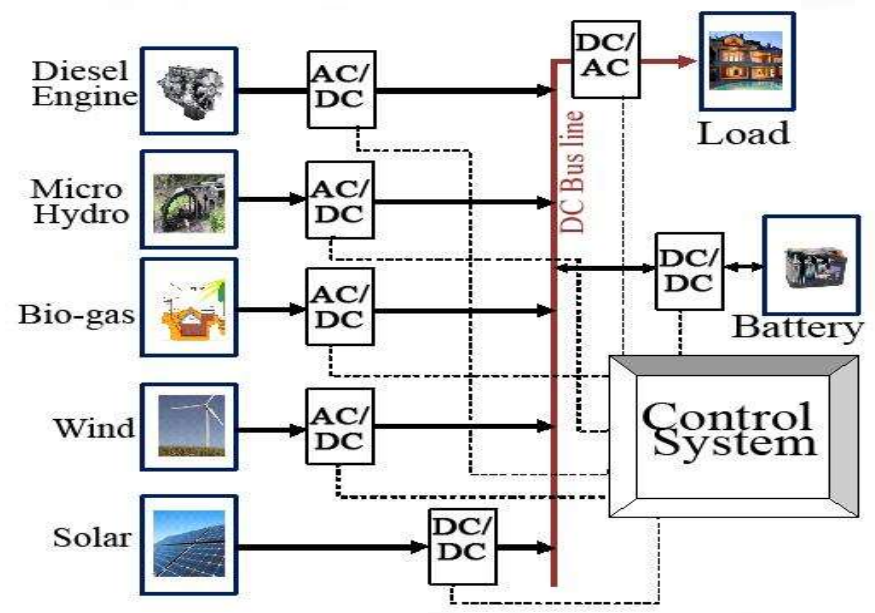

Considered Hybrid Energy System

\section{D) By using DSM strategy:}

DSM (demand side management) strategy is useful when the load required from the hybrid energy system is more. Normally, when the load required is very high at sometimes. Then we have to search for another source such as Diesel generator. Therefore, cost of unit generation increases rapidly. 
By using DSM strategy, we can reduce this problem. In this the total load is divided into three parts.

Those are,
a) Priority loads
b) Permanent loads
c) Deferrable loads (shiftable loads)

Priority loads which must be fulfilled when it is required by the customers (ex: CFLM, fan, radio, TV). Permanent loads which are continuously in on (ex: refrigerator). Deferrable load that can be shifts in time and once switched on power cannot be cut until the process is over (ex: Water pumps, crop threshing machine, Water heater, flourmill) [1]. In this, when load on the Hybrid energy system is high, then we have chance to shifts the deferrable load into particular time period where the total load due to other two loads (i.e. priority and permanent loads) are less. So that by using this strategy, we can give supply with less cost (since peak load in a particular period is less).

\section{RESULTS AND DISCUSSIONS}

Several sizing methods are reviewed to find the best optimum Hybrid energy system in terms of technology and economy. In this, every sizing method has its own advantage. The ease of leaving out a local minimum and the well-organized capability of finding the universal optimal is the most significant benefit of Gas when using hybrid system sizing [13]. The main advantage of GA has code-ability. However, it is more difficult and increase in time response with the GA approach if the no of parameters is larger. PSO method is more suitable when there is three of less than three components. If this number is exceeds 3 it would be more difficult in finding the global optimized method by using PSO technique.

In section-B gives review on different software tools used for obtaining optimized method of HES. In this optimization done by HOMER is most suitable method among all the software tools. The continuous upgradation of models and more user flexibility in the tools developed will be helpful for further research and stimulation of hybrid system application activities [10].

Section- $\mathrm{C}$ gives review on obtaining the low energy production. This method is useful by reducing dependency on non-renewable energy sources. Section-D gives the review on load management. This method is more useful when there is not having sufficient energy resources and also this method gives low cost hybrid energy system by reducing the total load on the system.

\section{CONCLUSION}

It is concluded that, every method has its own advantage in finding the optimal solution. Based on the given input we can choose the different methods for optimizing the Hybrid energy system.

\section{REFERENCES:}

[1] A. Chauhan and R. P. Saini, "Techno-economic optimization based approach for energy management of a stand-alone integrated renewable energy system for remote areas of India," Energy, vol. 94, pp. 138156,2016

[2] O. Hafez and K. Bhattacharya, "Optimal planning and design of a renewable energy based supply system for microgrids," Renew. Energy, vol. 45, pp. 7-15, 2012.

[3] O. Of, "I NTERNATIONAL J OURNAL OF," vol. 1, no. 2, pp. 359-366, 2010.

[4] S. Rajanna and R. P. Saini, "Modeling of integrated renewable energy system for electrification of a remote area in India," Renew. Energy, vol. 90, pp. 175-187, 2016.

[5] S. Rehman, M. Mahbub Alam, J. P. Meyer, and L. M. Al-Hadhrami, "Feasibility study of a windpv-diesel hybrid power system for a village," Renew. Energy, vol. 38, no. 1, pp. 258-268, 2012.

[6] B. F. Ronad and S. H. Jangamshetti, "Optimal cost analysis of wind-solar hybrid system powered AC and DC irrigation pumps using HOMER," 2015 Int. Conf. Renew. Energy Res. Appl. ICRERA 2015, vol. 5, pp. 1038-1042, 2015.

[7] N. C. Saha et al., "Modeling and performance analysis of a hybrid power system," 2013 Int. Conf. Informatics, Electron. Vis., pp. 1-5, 2013.

[8] K. Sasidhar, B. J. Kumar, and M. T. Student, "Optimal sizing of PV-Wind Hybrid energy system using Genetic Algorithm ( GA ) and Particle swarm optimization ( PSO )," vol. 4, no. 2, pp. 354-358, 2015.

[9] A. Singh and P. Baredar, "Techno-economic assessment of a solar PV, fuel cell, and biomass gasifier hybrid energy system," Energy Reports, vol. 2, pp. 254-260, 2016. 
[10] S. Sinha and S. S. Chandel, "Review of software tools for hybrid renewable energy systems," Renew. Sustain. Energy Rev., vol. 32, pp. 192-205, 2014.

[11] M. Usman, M. T. Khan, A. S. Rana, and S. Ali, "Techno-economic analysis of hybrid solardiesel-grid connected power generation system," $J$. Electr. Syst. Inf. Technol., pp. 1-10, 2017.

[12] P. K. Yadav and N. L. Prajapati, "An Overview of Genetic Algorithm and Modeling," vol. 2, no. 9, pp. 1-4, 2012.

[13] S. M. Zahraee, M. K. Assadi, and R. Saidur, "Application of Arti fi cial Intelligence Methods for Hybrid Energy System Optimization," Renew. Sustain. Energy Rev., vol. 66, pp. 617-630, 2016. 